\title{
Sobrevivência das Culturas em Skinner: Um Diálogo com o Materialismo Cultural de Harris ${ }^{1}$
}

\author{
Camila Muchon de Melo² \\ Júlio César Coelho de Rose \\ Universidade Federal de São Carlos
}

\begin{abstract}
RESUMO - Skinner estabeleceu a cultura como o terceiro nível de seleção pelas consequências no qual práticas são selecionadas de acordo com seu papel na sobrevivência da cultura. Assim, o objetivo deste estudo é apontar que o conceito de sobrevivência da cultura pode não ser suficiente para explicar práticas que não estabelecem uma relação direta com a sobrevivência. $\mathrm{O}$ percurso crítico foi estabelecido por meio de um diálogo com o materialismo cultural de Marvin Harris. Utilizou-se da análise conceitual dos textos, selecionados pela temática, dos dois autores. Conclui-se que sobrevivência da cultura como determinante da seleção de práticas culturais é problemática e de difícil sustentação. Sugeriu-se que a análise comportamental da cultura poderia avançar com as contribuições da antropologia.
\end{abstract}

Palavras-chave: sobrevivência da cultura, behaviorismo radical, materialismo cultural, práticas culturais, B. F. Skinner, Marvin Harris.

\section{Skinner's Survival Concept of Cultures: A Dialogue with Harris' Cultural Materialism}

\begin{abstract}
Skinner has established culture as a third selection level through which practices are selected according to their role in culture survival. Thus, this study aims to point out that the concept of culture survival may not be sufficient to explain practices that do not establish a direct relation with survival. A critical process was established through a dialogue with Marvin Harris' cultural materialism. The conceptual analysis of the texts was used, selected by thematic. It was concluded that culture survival as a determinant of selection of practices is problematic and difficult to sustain. It is suggested that the behavioral analysis of culture could advance with contributions from anthropology.
\end{abstract}

Keywords: Culture survival, radical behaviorism, cultural materialism, culture practices, B. F. Skinner, Marvin Harris.

B. F. Skinner (1938/1966) estabeleceu como objeto de estudo da ciência por ele proposta o comportamento. Em seus aspectos gerais, o conceito de comportamento não se refere apenas à resposta ou à ação de um organismo, ele se refere a uma relação. É a relação entre o organismo e seu ambiente que o constitui. O comportamento entendido dessa forma sugere também que ele pode ser conceituado como um processo, pois não é algo estático e imutável. Segundo Lopes (2008), uma vez que é parte do comportamento estar em constante mudança cabe incluir na definição de comportamento os processos comportamentais, assim, o comportamento na obra de Skinner pode também ser definido como um processo. Como salienta Skinner (1953/1965, p. 15) "O comportamento é uma matéria difícil, não porque seja inacessível, mas porque é extremamente complexo. Desde que é um processo, e

1 A primeira autora contou com bolsa de pós-doutorado da FAPESP (Processo 2008/56801-3). O segundo autor é bolsista de produtividade em pesquisa do CNPq. Os autores são filiados ao Instituto Nacional de Ciência e Tecnologia sobre Comportamento, Cognição e Ensino INCT-ECCE (Processos CNPq 573972/2008-7 e FAPESP (08/57705-8), que apoiou a preparação do manuscrito. Agradecemos o apoio da Cordenadora do INCT-ECCE, Professora Deisy de Souza.

2 Endereço para correspondência: Departamento de Psicologia, Laboratório de Estudos do Comportamento Humano, Universidade Federal de São Carlos, Caixa Postal 676, 13565-905, São Carlos, SP; E-mail: camuchon@hotmail.com não uma coisa, não pode ser facilmente imobilizado para a observação. É mutável, fluído e evanescente (...)”.

Além disso, o comportamento de um organismo é produto de interações que ocorrem no desenvolvimento de sua espécie, no tempo de sua vida e, no caso da espécie humana, é produto também das interações que ocorrem na cultura da qual são membros (Skinner, 1953/1965; 1966/1969; 1974/1976; 1981). Dito isto, há de se caracterizar também que para o behaviorismo radical de Skinner (1953/1965; 1974/1976), o comportamento é um processo ordenado, sujeito a leis naturais, ou seja, o comportamento é um processo determinado. Neste caso, a ciência do comportamento tem o papel de esclarecer suas uniformidades e torná-las explícitas.

Skinner não rejeitou na psicologia e em outras disciplinas das ciências humanas suas descobertas factuais, mas foi crítico veemente das explicações mentalistas predominantes em todas elas (e.g. Skinner, 1950; 1977). Além disso, defendeu explicitamente, em certo momento de sua obra, que a Análise do Comportamento era a ciência que poderia "agir para salvar o mundo" e, neste sentido, solucionar os problemas humanos mais amplos (Skinner, 1971/2002; 1987). O behaviorismo radical seria, de acordo com ele, um arcabouço teórico mais produtivo, que proveria uma fundamentação científica sólida para as outras ciências do homem. A visão skinneriana parece ter tido pouco impacto nas ciências humanas, sendo em geral rejeitada como reducionista e simplista (Skinner, 1974/1976). 
Poderíamos esperar, em particular, que a aplicação, feita por Skinner, do modelo de "seleção pelas consequências" às práticas culturais, assim como a importância atribuída por ele à cultura na determinação do comportamento humano, tivesse uma ressonância na Antropologia. Porém, entendemos que prevalece nessa disciplina uma visão distorcida da concepção skinneriana que praticamente elimina a sua influência. Uma exceção, que será tratada no presente artigo, é o materialismo cultural, do antropólogo norte-americano Marvin Harris. Contudo, não deixa de ser surpreendente, a pouca atenção que os estudiosos skinnerianos interessados em processos sociais e culturais têm dado às contribuições das ciências sociais, o que sugere a falta de diálogo entre o behaviorismo radical e outras teorias antropológicas.

Com poucas exceções, alguns esforços de diálogos ou embasamentos em teorias de disciplinas como a filosofia, a antropologia e a biologia têm sido escassos na literatura da Análise do Comportamento. Entretanto, quando esses esforços ocorrem parecem produzir um embasamento teórico que possibilita ao behaviorismo radical discutir questões ainda controversas sobre os fenômenos humanos (exemplos desse tipo podem ser vistos nos trabalhos de: Dittrich, 2008; Endemann \& Tourinho, 2007; Guerin, 1992; Malagodi, 1986; Vargas, 1985). Partindo-se de um modelo causal que concebe o comportamento humano como fruto de três histórias de variação e seleção, interlocuções com disciplinas que têm como seu objeto de estudo a evolução das espécies ou a evolução das culturas parecem ser imprescindíveis quando utilizamos o arcabouço teórico do behaviorismo de Skinner. Uma vez que, o diálogo com tais disciplinas pode favorecer a compreensão dos processos de variação e seleção na filogênese e na cultura, determinantes fundamentais para o comportamento de um indivíduo.

Alguns trabalhos também têm evidenciado a importância de debates sobre a teoria skinneriana, bem como da metodologia de pesquisa e da tecnologia comportamental empregada quando analistas do comportamento têm como seu objeto de investigação os fenômenos comportamentais que ocorrem na cultura (Andery, Micheleto \& Sério 2005; Biglan, 1995; Guerin, 1992, 1994; Lamal, 1991; Mattaini, 1996; Todorov \& Moreira, 2004). Trabalhos como os de Glenn e colaboradores (Glenn, 1986; 1988; Glenn \& Mallot 2004; Mallot \& Glenn, 2006) têm sugerido novos conceitos para a análise da cultura baseando-se na teoria behaviorista radical. Esses trabalhos visam, entre outros objetivos, cobrir possíveis lacunas teóricas presentes na proposta skinneriana de análise da cultura.

Nesse contexto de investigação, estudos experimentais também têm emergido com a possibilidade de apresentar uma importante ferramenta de investigação para embasar a análise comportamental da cultura. Esses estudos têm utilizado análogos de fenômenos comportamentais que ocorrem em ambientes sociais. Dentre outras questões, tais trabalhos tentam responder como as consequências dos operantes considerados "sociais" retroagem sobre o próprio comportamento do indivíduo e, como as consequências ditas "externas" ao grupo, ou seja, consequências que retroagem apenas ao comportamento em grupo e não individualmente, funcionam.
Assim, um estudo pioneiro na manipulação de possíveis análogos de consequências culturais foi conduzido por Wiggins (1969) com o objetivo de verificar se consequências externas ao grupo poderiam modificar as relações entre os componentes do grupo sem que para isso fosse necessária a manipulação de consequências dos operantes individuais e, além disso, responder à pergunta de quais consequências (internas ou externas ao grupo) exerceriam maior controle quando essas se apresentassem de maneiras opostas. Wiggins (1969) utilizou um jogo de matriz para responder sua pergunta. Os resultados do estudo sugeriram que manipular uma consequência "externa ao grupo" e contingente ao tipo de distribuição dos recursos ganhos no jogo (igual ou desigual), sem que essa consequência estivesse relacionada ao comportamento individual de cada participante, possibilitou uma distribuição dos ganhos de acordo com a contingência em vigor, o que sugeriu que a consequência externa poderia modificar o comportamento em grupo.

Utilizando-se do mesmo procedimento do estudo de Wiggins (1969) alguns estudos replicaram e ampliaram as variáveis de análise. O estudo de Vichi (2004) alterou algumas variáveis do procedimento original tais como: os grupos passaram por mais reversões entre os tratamentos e a mudança de tratamento ocorreu de acordo com um critério de estabilidade. Os resultados também sugeriram o estabelecimento de uma prática de distribuição de recursos de acordo com a contingência em vigor. O estudo de Martone (2008) investigou se as relações estabelecidas entre os participantes iniciais do jogo poderiam ser transmitidas a novos participantes ingênuos, entretanto, os resultados indicaram que a substituição dos jogadores não produziu efeitos significativos.

Utilizando-se outro jogo (intitulado Meta 2) os estudos de Bullerjhann (2009), Caldas (2009) e Oda (2009) investigaram análogos experimentais de metacontingências. Cabe ressaltar que esses estudos baseiam-se nos conceitos mais atuais sobre a metacontingência que enfocam as relações de dependência entre contingências comportamentais entrelaçadas (CCE), seus produtos agregados que dependem e ocorrem necessariamente contingentes ao entrelaçamento e as consequências culturais selecionadoras contingentes as CCEs, que não ocorrem necessariamente a cada ciclo das contingências comportamentais entrelaçadas (Glenn \& Malott, 2004; Malott \& Glenn, 2006). Os dados de Bullerjhann (2009) indicaram que as manipulações foram efetivas na produção de análogos experimentais de fenômenos sociais quando os análogos de consequências culturais são dependentes dos produtos das contingências entrelaçadas; os dados de Caldas (2009) sugeriram a formação de análogos de metacontingências, a seleção e a extinção de contingências comportamentais entrelaçadas; e os dados de Oda (2009) sugeriram que o comportamento verbal teve um papel importante na seleção, na recorrência e na transmissão de contingências comportamentais entrelaçadas entre gerações.

Além desses estudos, alguns pesquisadores utilizaram o jogo "Dilema do Prisioneiro" na investigação de fenômenos também considerados sociais, como os comportamentos de cooperação e de competição (Costa, 2009; Faleiros, 2009). Os resultados desses estudos sugeriram que a cooperação e a competição são influenciadas por consequências con- 
sideradas análogas às consequências "culturais" e que um componente verbal facilita essa influência.

Desse modo, tem sido sugerido que estudos experimentais recentes, como os descritos anteriormente, podem contribuir para a consolidação da análise comportamental da cultura e, além disso, seus resultados podem direcionar a solução de alguns problemas de ordem teórico-epistemológica (Carrara, 2008). Com efeito, todos esses estudos descritos indicam que a análise comportamental da cultura é recente e demanda que análises teóricas, empíricas e aplicadas sejam ampliadas na temática em questão.

Diante disso, o presente artigo tem o objetivo de analisar um aspecto da teoria skinneriana sobre a evolução das culturas a partir, principalmente, das contribuições da teoria antropológica do materialismo cultural de Marvin Harris. O materialismo cultural é um paradigma antropológico que compartilha muitos princípios teóricos e epistemológicos com o behaviorismo radical, tese defendida por seu proponente Marvin Harris (1986/2007). Segundo esse autor, assim como o behaviorismo radical, o materialismo cultural se opõe ao reducionismo biológico e às teorias psicológicas que elevam a mente a um status causal do comportamento. Essa teoria tem sido discutida por alguns analistas do comportamento quando seu objeto de estudo é a cultura (Glenn, 1988; Malagodi, 1986; Malagodi \& Jackson, 1989; Malott, 1988; Vargas, 1985).

Skinner defende que a evolução da cultura se dá por processos de variação e seleção; nesses processos as práticas culturais seriam as unidades sujeitas à seleção de acordo com seu papel na sobrevivência das culturas (Skinner, 1981; 1987). Essas unidades originam-se do comportamento operante, mas operantes tornam-se práticas culturais quando são reforçados por uma cultura, transmitidos como parte de um ambiente social entre membros de uma mesma cultura, entre gerações ou entre culturas (Skinner, 1971/2002). Com efeito, Skinner (1981) sugere que sobrevivência das culturas é o que determina a manutenção e a transmissão de suas práticas. Como ele salientou "E quer gostemos disto ou não, a sobrevivência é o critério final" (Rogers \& Skinner, 1956, p. 1065).

Sendo assim, este estudo pretende apresentar: $1^{\circ}$ ) a posição skinneriana de que a seleção de práticas culturais se fundamenta no valor dessas práticas para a sobrevivência da cultura; $2^{\circ}$ ) a teoria de Marvin Harris sobre a seleção de práticas culturais, ou seja, a tese do determinismo da infraestrutura e sua crítica à explicação skinneriana nessa temática e $3^{\circ}$ ) nossos questionamentos sobre a posição skinneriana de que a seleção de práticas culturais se fundamenta no valor dessas práticas para a sobrevivência da cultura.

O método utilizado foi uma análise conceitual de parte da obra de Skinner. Assim, o nosso principal objeto de investigação foi o próprio texto skinneriano. Algumas correntes de pensamento acreditam que a análise do texto de um pensador consiste em apresentar a tese do autor da forma como ele a empreendeu; entretanto, baseando-nos em alguns pressupostos do método epistemológico hermenêutico, acreditamos que essa missão seria impossível, uma vez que o pesquisador apresenta uma história cultural e uma base de conhecimentos diferentes das do autor do texto original (Abib, 1996). Nesse sentido, a análise conceitual de um tema ou de uma obra implica uma interpretação e a construção de novos significados. Assim, este artigo apresenta uma interpretação possível, não a única, sobre o conceito de sobrevivência das culturas em Skinner. Para isso, textos fundamentais dos dois autores foram analisados. Ou seja, os textos foram escolhidos pela temática, no caso de Skinner e, no caso de Harris, utilizou-se o livro "Materialismo Cultural", de 1979, em que ele apresenta sua tese central sobre a cultura e outros dois artigos nos quais ele discute diretamente o behaviorismo radical de Skinner: "Group and individual effects in selection", de 1984, no qual Harris comenta o artigo skinneriano "Selection by consequences", de 1981, e a apresentação realizada na $12^{\mathrm{a}}$ conferência anual da "Association for Behavior Analysis" (1986), que foi transcrita e posteriormente publicada no "The Behavior Analyst" com o título: "Cultural materialism and behavior analysis: Common problems and radical solutions" publicado em 2007. Deste modo, passemos à interpretação proposta neste estudo.

\section{B. F. Skinner e o conceito de sobrevivência das culturas}

A teoria psicológica do behaviorismo radical skinneriano defende o papel selecionista do ambiente (Skinner, 1981). Além da seleção natural, apropriada da teoria darwinista, que sugere que algumas características físicas e comportamentais são produtos de contingências de sobrevivência das espécies, esse autor defende que os processos de variação e seleção estão presentes também nas histórias ontogenética e cultural dos indivíduos. Assim, os comportamentos dos indivíduos e as práticas de uma cultura são produtos de processos de variação e seleção.

O modelo de seleção pelas consequências de Skinner pressupõe a existência de variações que podem ser selecionadas em contingências de sobrevivência da espécie, contingências de reforçamento ou contingências culturais. No terceiro nível de variação e seleção, o campo da evolução das culturas, as variações são as práticas de uma cultura (Skinner, 1981). Não há, no modelo de seleção pelas consequências, lugar para um propósito no sentido teleológico.

Nesse contexto, Skinner argumenta que algumas práticas culturais possibilitam o fortalecimento da cultura; nesse caso afirma-se que tais práticas possuem "valor de sobrevivência" positivo. Em um sentido inverso, quando algumas práticas não fortalecem uma cultura afirma-se que essas apresentam "valor de sobrevivência" negativo (Dittrich, 2004). Para as práticas ditas com "valor de sobrevivência" positivo, Skinner (1971/2002) denominou como práticas que produzem o "bem da cultura", ou seja, são práticas que fortalecem a cultura no sentido de torná-la mais apta a resolver seus problemas. Entretanto, a sobrevivência da cultura como uma consequência de certas práticas culturais não é uma consequência que possa exercer papel reforçador nas contingências de reforçamento: "a escala temporal através da qual podemos aferir a sobrevivência da cultura (décadas ou séculos) é muito diferente da escala temporal na qual ocorre o reforço do comportamento operante" (Dittrich, 2003, p.19). Portanto, trabalhamos em prol da cultura não porque sua sobrevivência nos é reforça- 
dora, mas porque outras consequências mais imediatas nos levam a fazer isso.

Vejamos um exemplo citado por Skinner (1981, p. 502): "Um melhor modo para fazer uma ferramenta, cultivar alimentos ou ensinar uma criança é reforçado por suas consequências - a ferramenta, o alimento, ou o ajudante útil, respectivamente". Esses são exemplos de práticas que podem, como consequência, fortalecer uma cultura; entretanto, outras variáveis devem estar presentes nos ambientes daqueles que a praticam. Pensemos que artesãos habilidosos fortaleçam uma determinada cultura. Logo, a prática de ensinar um aprendiz pode produzir consequências que fortaleçam essa cultura, mas a própria consequência de "ganhar um ajudante útil" deve ser uma das variáveis que mantém o comportamento do artesão de ensinar e é essa consequência que está no âmbito das contingências de reforçamento.

Pode-se argumentar que quando Skinner trata das questões relacionadas com a sobrevivência da cultura, ele percorre dois principais argumentos: 1) a sobrevivência de uma cultura de acordo com os processos de variação e seleção e 2) a defesa de que a tecnologia do comportamento pode contribuir para a sobrevivência da humanidade ao planejar novas práticas culturais e estabelecer contingências seletivas para práticas que fortaleçam uma cultura. Enfocaremos apenas o primeiro argumento por sua importância neste artigo.

Assim, Skinner (1987) defende que a evolução da cultura e sua possível sobrevivência ocorrem por processos de variação e seleção. Entretanto, esses processos apresentam algumas "falhas" (Skinner, 1990). A primeira "falha" nos processos de variação e seleção estaria no fato de que as contingências filogenéticas selecionam características biológicas ou comportamentais da espécie que são eficientes apenas para aquele período de sua história evolutiva, ou seja, a seleção natural "prepararia" a espécie apenas para um futuro no qual as contingências fossem similares àquelas responsáveis pela sua seleção. Skinner $(1987,1990)$ salientou que a evolução do processo de condicionamento operante permitiu a correção dessa "falha", pois esse processo permite que o indivíduo adquira comportamento apropriado a um novo ambiente durante o tempo de sua vida. Contudo, Skinner (1987) aponta que o problema persiste, uma vez que também o condicionamento operante produz comportamento "apropriado" para um futuro que se assemelhe com o passado que o selecionou.

Para o autor, muitos dos nossos problemas atuais são originados das "falhas" nos processos de variação e seleção. Skinner (1987) argumenta que por meio das contingências filogenéticas da espécie humana algumas suscetibilidades a certos tipos de reforçadores evoluíram e foram selecionadas, possivelmente porque foram importantes para sua sobrevivência. Entretanto, essas suscetibilidades herdadas acarretaram alguns problemas atuais de acordo com as contingências ambientais que vivemos hoje. Skinner (1987) sugere que os problemas acarretados por essas suscetibilidades são decorrentes dos processos de variação e seleção.

Assim, com o objetivo de trazer contribuições para a discussão sobre o conceito de sobrevivência da cultura de Skinner, partimos para um diálogo com alguns pressupostos do materialismo cultural de Marvin Harris.

\section{O conceito skinneriano de sobrevivência das culturas: um diálogo com o materialismo cultural de Marvin Harris}

Para o materialismo cultural, a cultura é "o agregado de classes, com destacadas classes de respostas operantes, socialmente condicionadas, as quais são associadas com um grupo humano particular e que tendem a ser replicadas intra e através das gerações" (Harris, 1986/2007, p. 38). As classes de operantes socialmente condicionadas ocorrem quando muitos indivíduos exibem a mesma classe de operantes e essa classe passa a existir mesmo quando esses indivíduos morrem. Para Harris (1979/1980), a sociedade é entendida como o grupo social maior que apresenta uma ampla gama de interações comportamentais, contempla os repertórios aprendidos de pensamento e de ações exibidos pelos membros de um grupo social e transmitidos intra e entre gerações. Esses repertórios contribuem para a continuidade da população e para a vida social.

Assim como para Skinner (1971/2002), para Harris (1986/2007) as classes de operantes condicionadas culturalmente, ou as práticas culturais, são comumente definidas em termos como caçar, coletar, guerrear, entre outros. Segundo Harris (1986/2007), essas classes não existem isoladas uma das outras e apresentam entre si pré-condições de existência. Ou seja, não existiriam as festas sem a caça, a caça sem os caçadores e os caçadores sem a lança, fatos sustentados por dados empíricos.

Para Harris (1986/2007), as peculiaridades dos sistemas culturais não são devidas às características humanas designadas como a mente, os desejos, o pensamento simbólico, ou mesmo o comportamento verbal, como defendem alguns antropólogos. Esse autor defende que essas peculiaridades são decorrentes da imensa quantidade do número de indivíduos e de respostas que subscrevem a abstração e a classificação dos componentes socioculturais e de todos os sistemas culturais. Nesse aspecto, o materialismo cultural e o behaviorismo radical concordam que nenhum novo princípio comportamental é necessário para tratar dos fenômenos comportamentais no nível da cultura. Entretanto, essas perspectivas se deparam com o problema de como descrever o comportamento, não de indivíduos sozinhos, mas o comportamento que faz parte de um sistema cultural.

Skinner (1981) sugeriu que a evolução da cultura se dá por processos de variação e seleção em que novos repertórios comportamentais surgem como operantes no comportamento de indivíduos, alguns dos quais são transmitidos entre gerações e assim, foram selecionados pelas contingências culturais vigentes; constituem as práticas de uma cultura. Harris (1986/2007) argumenta que para descrever a seleção de repertórios operantes de uma cultura é necessário investigar o efeito desses operantes na cultura. Uma vez que, os operantes podem assumir um número infinito de funções, há a necessidade de especificar quais são as funções que servem para os repertórios culturais, o que possibilita-nos algum progresso no estudo das especificidades do processo de seleção no nível da cultura.

Skinner $(1971 / 2002 ; 1981 ; 1984 ; 1990)$ argumenta que as práticas culturais que foram selecionadas por processos de variação e seleção são aquelas que contribuíram para a 
sobrevivência da cultura, embora o autor também saliente que muitas práticas que não fortalecem uma cultura podem coexistir com práticas que a fortalecem. Assim, a "função" primordial dos operantes culturalmente estabelecidos seria a própria sobrevivência da cultura. Segundo Harris (1986/2007), a sobrevivência da cultura como a principal função que "governa" a seleção nesse nível, especifica ainda três derivações: a coesão do grupo, uma ação efetiva com relação ao ambiente físico e uma relação efetiva com relação a outros grupos. Esse autor critica a noção de sobrevivência da cultura como determinante da seleção de práticas culturais. Para ele essa é uma formulação inadequada, pois a maioria das inovações culturais que foram selecionadas pelas consequências não apresentava evidências de como poderiam contribuir para a sobrevivência da cultura no momento em que foram selecionadas. Esse autor argumenta que o teste sobre se uma inovação cultural teve um efeito sobre a sobrevivência da cultura não pode ser a medida de "sobrevivência da cultura", uma vez que se assim fosse todos os componentes de uma cultura que têm sobrevivido teriam essa característica. Segundo Harris (1986/2007), algumas estratégias como as político-militares podem ser selecionadas pelos seus efeitos imediatos de sobrevivência no grupo. Entretanto, é mais difícil apontar as mesmas consequências para os grupos quando as inovações culturais são provenientes das atividades religiosas, das artes ou das ideologias, por exemplo. Esse autor ainda salienta que inovações desse tipo podem ocorrer durante milhares de anos antes que seu efeito sobre a sobrevivência do grupo passe a ser objeto de seleção.

Skinner (1971/2002; 1981), por outro lado, quando apresenta seu modelo de seleção pelas consequências no qual a cultura é o produto de processos de variação e seleção, discute práticas culturais nas quais é plausível atribuir um valor de sobrevivência. Entretanto, a nosso ver, frequentemente são práticas pouco complexas se compararmos com práticas existentes em diversas culturas e descritas por muitos antropólogos. Atribuir um valor de sobrevivência positivo em práticas como caçar, cultivar alimentos, acumular riquezas, por exemplo, parece mais plausível. Por outro lado, exemplos mais complexos como o de práticas culturais que compõem o potlatch, descritas por Mauss (1925/1974), e o kula, descritas por Malinowski $(1922 / 1984)^{3}$ são extremamente elaboradas,

3 No potlatch, descrito inicialmente sobre a civilização escandinava, presentes são dados, mas quando isso ocorre há a "regra", não necessariamente explícita, de que o presente dado deve ser recebido e retribuído. O "presente" pode incluir uma ampla gama de possibilidades. Segundo Mauss (1925/1974, p. 45), "O que trocam não são exclusivamente bens e riquezas, móveis e imóveis, coisas economicamente úteis. Trata-se, antes de tudo, de gentilezas, banquetes, ritos, serviços militares, mulheres, crianças (...) a circulação de riquezas constitui apenas um termo de um contrato muito mais geral e muito mais permanente". $\mathrm{O}$ kula foi descrito também como uma espécie elaborada de trocas entre diversas tribos nas ilhas Trobriand e seus arredores. Ao descrever o kula Malinowski (1922/1984) ressalta: "A troca cerimonial de dois artigos um pelo outro é o aspecto fundamental e central do kula (a troca de colares por braceletes) (...)" (p.72). (...) "É fácil observar que, no fim das contas, não só os objetos da cultura material, mas também os costumes, canções, temas artísticos e influências culturais gerais também viajam ao longo das rotas do kula. O que se verifica, então, é um vasto encadeamento de relações intertribais numa grande instituição que incorpora milhares de pessoas, todas elas unidas por uma paixão comum pelas transações do kula" (p. 78). envolvem um grande número de indivíduos e foram transmitidas entre diversos grupos e gerações de suas respectivas culturas. Em alguns casos de trocas, envolvidas no potlatch $\mathrm{e}$ no kula, as "coisas" dadas nas relações de trocas podem ser retribuídas anos após serem oferecidas. Entretanto, defendemos que os rituais envolvidos em tais práticas não apresentam, pelo menos diretamente, um valor de sobrevivência para a cultura praticante. Nesse aspecto, questionamentos sobre as razões pelas quais práticas culturais desse tipo são mantidas são fundamentais para entendermos as culturas humanas $\mathrm{e}$ a crítica de Harris torna-se então pertinente.

Um possível contra-argumento skinneriano seria que, de acordo com seu modelo de causalidade, o comportamento humano ao participar de práticas culturais, é primeiramente selecionado ou modelado em contingências de reforçamento. Assim, teríamos uma explicação do porquê algumas práticas são mantidas a despeito da sobrevivência de um grupo, ou seja, por suas consequências mais imediatas para o comportamento dos indivíduos. Entretanto, tais práticas apenas seriam mantidas entre gerações se de alguma forma contribuíssem para a sobrevivência da cultura. Esse é o princípio do processo de variação e seleção, ou seja, aquilo que contribuiu para a sobrevivência de um grupo acaba por ser selecionado juntamente com essa cultura. Pensemos em uma situação ideal hipotética: se uma cultura apresenta apenas práticas que não contribuem para a sua sobrevivência, mas tais práticas são mantidas (certamente por um período curto de tempo em relação à sobrevivência de uma cultura que é medida em milhares de anos) por contingências de reforçamento, essa cultura provavelmente se extinguirá. Assim, se essa cultura se extinguir, poderíamos sugerir que aquelas práticas não contribuíram para a sobrevivência do grupo, embora tivessem sido mantidas por um período de tempo. Entretanto o argumento de Harris ainda parece válido. É intrigante que muitas práticas culturais, nas quais um valor de sobrevivência não é facilmente aferido, mantenham-se por diversas gerações sem que um "prejuízo" para o grupo praticante seja identificado. Ou mesmo, sem que qualquer contribuição para a sobrevivência do grupo seja reconhecida.

Skinner (1966/1969) ainda aponta que características "não-adaptativas" podem ser selecionadas quando os organismos se tornam cada vez mais sensíveis às consequências. Neste sentido, práticas culturais "não-adaptativas" podem sobreviver juntamente com práticas "adaptativas". Segundo Skinner (1966/1969, p. 177), "Todas as características atuais de um organismo não contribuem necessariamente para a sua sobrevivência e procriação, todavia são 'selecionadas"”.

Portanto, para Skinner, algumas práticas de uma cultura no caso do terceiro nível seletivo, que não apresentam valor de sobrevivência positivo podem, mesmo assim, ser selecionadas juntamente com outras práticas culturais que contribuíram para a sobrevivência da cultura. Ou seja, um possível argumento skinneriano seria que se podemos nos deparar com práticas de uma cultura que foram selecionadas embora não tivessem contribuído para sua sobrevivência, isso provavelmente ocorreu porque as práticas com valor de sobrevivência negativo foram selecionadas juntamente com práticas com valor de sobrevivência positivo e como resultado a cultura sobreviveu. 
Voltemos ao pensamento de Harris. Esse autor enfatiza que se a "função" das inovações culturais for utilizada como uma medida da efetividade para o grupo, nós devemos primeiramente entender que os seres humanos possuem algumas necessidades físicas, químicas, biológicas, sociológicas e psicológicas. Neste sentido, Harris (1986/2007) argumenta que Skinner abarca tais necessidades quando explica a aquisição do comportamento de acordo com as suscetibilidades inatas ao reforço, como as suscetibilidades do comportamento ser reforçado por comida, sexo, contato corporal e proteção para enfermidades. Para esse autor, essa lista não é exaustiva, mas satisfaz o papel de uma ciência parcimoniosa e é suficiente para definir uma coleção de funções básicas desempenhadas pelos operantes que são objeto de seleção em uma cultura. Mas ainda seriam apenas "funções básicas".

Segundo Harris (1986/2007), tais necessidades ou suscetibilidades asseguram a seleção de todos os componentes e subcomponentes de uma cultura particular, embora não se possa afirmar que para cada necessidade humana haja um componente cultural que seja exclusivamente condicionado em contingências relacionadas com uma necessidade específica. Dois exemplos interessantes descritos por Harris são a enculturação ${ }^{4}$ da aversão da população Hindu pelo abate de gado e consumo dessa carne e a enculturação de costumes conjugais poligâmicos; para ambos os exemplos os comportamentos relacionados não foram modelados exclusivamente pelo reforçamento com comida e sexo, respectivamente. Segundo Harris (1986/2007), a carência de uma relação direta entre as necessidades humanas, ou em uma linguagem skinneriana entre as suscetibilidades humanas, e as contingências de reforçamento é compensada pela relação de interação e interdependência da maioria dos componentes dos sistemas socioculturais e de subsistência.

\section{A tese do materialismo cultural sobre a evolução das culturas}

Uma das teses do materialismo cultural apresentada por Harris $(1979 / 1980 ; 1986 / 2007)$ define que uma cultura apresenta três principais tipos de sistemas: 1) o sistema que pertence à infraestrutura, que engloba as formas de produção e reprodução; 2) o sistema que pertence à estrutura, que engloba a economia doméstica e a política; e 3) o sistema que pertence à superestrutura, que engloba as artes em todas suas formas, a religião, a ciência e a educação.

O sistema da infraestrutura contempla os modos de produção e reprodução. $\mathrm{O}$ modo de produção relaciona-se com os comportamentos que satisfazem as condições mínimas de subsistência. Neste caso, engloba a tecnologia e as práticas empregatícias que expandem ou limitam a produção de subsistência básica, como a produção de comida e outras formas de energia. O modo de reprodução relaciona-se com os comportamentos que satisfazem as condições de manutenção do tamanho do grupo; assim, as práticas tecnológicas ou empregatícias que têm o objetivo de expandir, limitar ou

4 Do inglês enculturation, que se refere ao processo de aquisição de uma cultura. manter o tamanho da população são práticas que satisfazem ao modo de reprodução (Harris, 1979/1980).

Assim sendo, se as necessidades básicas humanas naturalmente determinadas devem ser alcançadas, alguns componentes da cultura estarão envolvidos na produção de bens e serviços indispensáveis. Exemplos disso seriam as produções de comida, de abrigo, de vestuário, de cuidados médicos e uma economia de subsistência (Harris, 1986/2007).

O segundo sistema, o sistema estrutural, como dito anteriormente, compreende a economia doméstica e a economia política. Esse sistema satisfaz a função de cumprir as necessidades sexuais humanas e as necessidades econômicas. Segundo Harris (1979/1980), a economia doméstica ocorre no interior dos domicílios e cumpre a função de alimentação, de cuidado e de reprodução. Por outro lado, a economia política ocorre fora dos domicílios e cumpre a função de regular as relações entre os domicílios, entre os grupos não domésticos e entre uma população e outra.

O terceiro sistema, o sistema da superestrutura, contempla as artes em todas as suas formas, a religião, a ciência e a educação. Segundo Harris (1979/1980, 1986/2007), os componentes desse sistema estão remotamente relacionados com a satisfação das necessidades básicas humanas naturalmente determinadas em comparação com os componentes do sistema da estrutura e de maneira mais remota se comparado aos componentes do sistema da infraestrutura (Harris, 1986/2007).

Para o materialismo cultural, a direção da evolução sociocultural é determinada probabilisticamente pelas consequências das inovações culturais em relação ao equilíbrio entre o custo e o benefício para a produção e a reprodução. Desse modo, a probabilidade de uma inovação que emergiu de um sistema cultural ser transmitida é determinada por seus resultados, se esses são ou não mais favoráveis ou menos favoráveis no equilíbrio da relação de custo-benefício para a produção e a reprodução. Para Harris (1979/1980; 1986/2007), as mudanças nos componentes da infraestrutura determinam probabilisticamente os componentes da estrutura e da superestrutura. Esse autor defende que o sistema infraestrutural é a principal conexão entre a natureza e a cultura. Uma vez que a ação humana está sujeita a certas restrições ecológicas, químicas e físicas (como o fato de que os seres humanos gastam energia para obter energia e outros produtos de subsistência) esse sistema promove a interação com as principais práticas culturais que pretendem superar tais restrições.

Assim, destaca-se que o materialismo cultural defende um determinismo infraestrutural. Nesse caso, mesmo que algumas práticas que pertencem aos sistemas estruturais ou superestruturais não favoreçam a sobrevivência do grupo, elas podem manter-se desde que o sistema da infraestrutura seja efetivo. Harris (1986/2007) salienta que isso fica evidente quando investigamos a história de uma cultura durante longos períodos. Desse modo, mesmo que alguns componentes dos sistemas estruturais ou superestruturais pareçam ser os responsáveis pela manutenção de uma cultura, uma investigação longínqua mostrará, segundo esse autor, a determinação da infraestrutura. Um exemplo dado por Harris (1986/2007) consiste na suposta primazia da religião no Irã contemporâneo; se não investigarmos a história dessa cultura, poderíamos 
afirmar que a religião (sistema da superestrutura) dominaria os componentes do sistema infraestrutural. Entretanto, o autor destaca que embora o fundamentalismo xiita tenha modificado as atividades dos iranianos em relação à produção e à reprodução, a derrubada do Shah (governo iraniano anterior ao fundamentalismo xiita) ocorreu principalmente pela detenção dos recursos petrolíferos do Irã (condições da infraestrutura). Segundo Harris (1986/2007), se os sistemas que não pertencem à infraestrutura (como a política e a religião) fossem essenciais à sobrevivência de uma cultura, não teríamos como explicar por que organizações em grupo existiram por centenas de milhares de anos, por que aldeias foram raridades até oito mil anos antes de Cristo e por que os primeiros Estados só surgiram há seis mil anos.

Com relação aos processos seletivos no nível da cultura, Harris $(1979 / 1980 ; 1984 / 1988)$ apresenta uma posição parcialmente análoga à posição skinneriana. Ele defende que a seleção de repertórios comportamentais não é descrita por termos metafísicos como força, pressão ou impulso, mas por princípios biopsicológicos concretos pertinentes ao comportamento dos indivíduos que participam de um sistema cultural. Para esse autor, os processos relacionados à seleção de trajetórias evolucionárias dos sistemas socioculturais operam essencialmente no nível do indivíduo, defesa análoga à posição skinneriana. Para Harris (1979/1980; 1984/1988), os indivíduos seguem um curso de ação ao invés de outro e como resultado ocorre uma mudança nos padrões agregados. Embora essa asserção não exclua a possibilidade de que alguns traços socioculturais sejam selecionados pela sobrevivência diferencial de sistemas socioculturais inteiros, ou seja, pela seleção do grupo, o autor argumenta que muito cedo na história da humanidade a competição entre grupos foi, e ainda é, presente. A competição entre grupos pode promover a extinção de sistemas socioculturais completos. Entretanto, exemplos desse tipo são consequências da seleção que operam através de indivíduos.

Assim, esse autor defende que se alguns padrões de comportamento são selecionados, essa seleção ocorre quando alguns ou todos os membros de um grupo obtiveram sucesso com tais repertórios. Essa afirmativa também não significa que a seleção ocorre de acordo com o "bem maior" para um "número maior” de indivíduos. Harris (1979/1980) salienta que alguns padrões culturais são selecionados embora não favoreçam uma parte do grupo; como exemplo está o uso da burca (vestimenta feminina que cobre todo o corpo e é utilizada por alguns grupos mulçumanos) que favorece o controle político e doméstico dos homens em relação às mulheres.

\section{A sobrevivência da cultura em Skinner: um conceito em construção}

A posição de Harris (1979/1980; 1984/1988; 1986/2007) sobre as questões culturais e seu diálogo com o behaviorismo radical pode contribuir para as discussões presentes na análise comportamental da cultura. Primeiro, devemos nos questionar se a medida de sobrevivência é realmente efetiva. Como mesmo salientou Harris (1986/2007), algumas práticas são selecionadas a despeito do fortalecimento ou não de uma cultura. Skinner provavelmente concordaria com essa afirmativa. Como discutimos anteriormente, muitos operantes e muitas práticas de uma cultura são selecionados simplesmente pelo fato de que os organismos tornaram-se cada vez mais sensíveis às consequências de seu comportamento. No caso da cultura, muitas práticas podem apresentar valor de sobrevivência negativo. A questão seria então uma relação de custo-benefício, como enfatizou Harris? A resposta poderia ser afirmativa e, sendo assim, um número essencial de práticas culturais que apresentem valor de sobrevivência positivo seria necessário para o fortalecimento de uma cultura.

A medida de sobrevivência, embora não explique todas as práticas que se mantêm, de acordo com o pensamento de Harris, ainda parece ser uma boa medida se estamos preocupados com o planejamento de uma cultura. Harris (1979/1980; 1986/2007) enfatizou o determinismo da infraestrutura e esse é outro argumento bem interessante no diálogo com o behaviorismo radical skinneriano. Acreditamos que Skinner não concordaria que apenas as práticas relacionadas a esse sistema favoreceriam a sobrevivência de um grupo. Baseando-se nos pressupostos do behaviorismo radical, poderíamos argumentar que qualquer prática cultural que colaborasse para a resolução dos problemas de um grupo poderia ser uma prática com valor de sobrevivência positivo, e, sendo assim, ela poderia ser uma prática do sistema estrutural ou superestrutural; exemplos desse tipo podem ser algumas práticas relacionadas à educação, às artes e à ciência.

Entretanto, é interessante admitirmos que de alguma forma deva haver práticas culturais que mantenham a subsistência básica e o tamanho físico de um grupo, ou seja, práticas da infraestrutura. Essas práticas apresentariam valor de sobrevivência positivo por definição? Provavelmente sim, não há como uma cultura sobreviver se uma parte considerável de seus habitantes não sobreviver. Nesse sentido, estaríamos, em certo sentido, contrariando as posições de Skinner de que o valor de sobrevivência é o "critério final" na manutenção das práticas de uma cultura. As práticas que contribuem diretamente com a manutenção física de uma cultura apresentam valor de sobrevivência positivo, mas outras inúmeras práticas que coexistem com "práticas de sobrevivência" não poderiam ser explicadas com os mesmos argumentos. Outros mantenedores, que não suas relações diretas com o fortalecimento de uma cultura, poderiam ser as "razões" da permanência dessas práticas em um grupo. Assim, parece que, se nosso argumento for plausível, a Análise do Comportamento necessita de mais investigações, no campo dos fenômenos que ocorrem em uma cultura, para entender porque práticas são mantidas mesmo quando não apresentam uma relação direta com a sobrevivência de uma cultura. Não basta explicar que as "razões" encontram-se nas contingências vigentes, precisamos buscar quais seriam essas contingências e investigá-las de formas mais minuciosas.

Cabe ainda questionar que a sobrevivência genética de um grupo não garante a sobrevivência de uma cultura. Podemos imaginar também que a própria sobrevivência dos membros de um grupo possa ser decorrente de uma mudança profunda nas práticas culturais ao ponto de atribuirmos ao grupo uma "nova cultura". Um exemplo poderia ser a transformação pela qual grande parte da cultura aborígene australiana passou (povo nativo da Austrália). Embora ainda 
existam na Austrália algumas comunidades de Aborígenes que vivem isoladas da cultura australiana de origem inglesa e que mantêm parte de suas práticas nativas, outra parte considerável da população aborígene teve suas práticas culturais amplamente modificadas após a colonização inglesa. Crianças Aborígenes foram retiradas de suas famílias e adotadas por famílias de origem inglesa ou colocadas em orfanatos com o objetivo de ensinar os costumes dos "homens brancos" e erradicar os costumes Aborígenes em um período conhecido como o da "geração perdida". Esse é um exemplo da sobrevivência genética de uma população com ampla deterioração das práticas culturais que foram típicas de uma cultura. ${ }^{5}$

Segundo Dittrich (2004), de acordo com uma posição behaviorista, o valor de sobrevivência de uma cultura dependerá do valor de sobrevivência do conjunto de suas práticas e das relações entre elas, mas o que determina se uma prática tem valor de sobrevivência positivo são as contingências vigentes. Entretanto, esse autor parece ainda concordar com o argumento de Harris, de que as práticas relacionadas ao sistema infraestrutural apresentam valor de sobrevivência intrínseco. Vejamos o que ele diz: "Algumas práticas culturais possuem, presumivelmente, valor de sobrevivência 'intrínseco': são aquelas práticas que promovem a sobrevivência de qualquer cultura, em qualquer época, pois são indispensáveis para a subsistência e reprodução de seus membros" (Dittrich, 2004, p. 247. Grifo do autor). Não obstante, esse autor enfatiza que esse argumento é baseado na estabilidade de certas contingências de sobrevivência da espécie. Exemplo disso é o fato de que os membros de uma cultura devem alimentar-se para sobreviver e transmitir suas práticas, e, assim, certas práticas culturais como as relacionadas à produção de alimentos podem aparentar valor "intrínseco" de sobrevivência. Contudo, segundo Dittrich (2004), em última análise, são as contingências que determinam o valor de sobrevivência das práticas culturais; nesse sentido, nenhuma prática cultural possuiria um valor de sobrevivência intrínseco. Entretanto, nossa questão ainda permanece: quais são as contingências vigentes? Quais são as relações entre as práticas culturais que determinam a sobrevivência de uma cultura?

Ou seja, em seus aspectos gerais, poderíamos argumentar que de acordo com uma perspectiva skinneriana, uma cultura torna-se mais forte quando possibilita que práticas com valor de sobrevivência positivo mantenham-se e que práticas com valor de sobrevivência negativo extingam-se. O valor de sobrevivência de uma prática cultural é variável, ou seja, depende das contingências vigentes; entretanto, poderíamos afirmar que algumas práticas parecem contribuir para o fortalecimento de qualquer cultura e em qualquer época, como aquelas relacionadas à sobrevivência genética do grupo. Portanto, independentemente de a qual sistema uma prática cultural pertença, ela pode contribuir para o fortalecimento de uma cultura desde que possibilite "variabilidade benéfica"

5 Muitas mudanças na nossa própria cultura poderiam ser apontadas, por observadores externos, como deterioração cultural, embora às vezes possam, para os próprios membros de nossa cultura, ser identificadas como "progresso". e/ou a manutenção de "práticas com valor de sobrevivência positivo". Ou seja, que ela "satisfaça" as condições essenciais dos processos de variação e seleção. Assim, a visão de Skinner não descarta a importância de práticas de subsistência, mas de acordo com seus pressupostos, independentemente de a qual sistema uma prática pertença, ela pode contribuir para o fortalecimento de uma cultura dependendo das contingências em vigor.

Pensemos nas práticas educacionais e nas artes. Se assumirmos uma perspectiva relacionada ao materialismo cultural, genericamente essas práticas estariam mais relacionadas à estrutura e à superestrutura. Entretanto, elas podem contribuir para a sobrevivência de uma cultura, de acordo com a visão skinneriana. A educação pode colaborar para a transmissão de práticas culturais importantes para a sobrevivência de um grupo, as artes em todas as suas formas podem promover o comportamento criativo e assim, favorecer a emergência de novos comportamentos quando uma cultura depara-se com contingências adventícias e necessita de um comportamento original para a solução de um problema crucial à sua sobrevivência. Portanto, de acordo com uma perspectiva skinneriana, as práticas que pertencem aos sistemas estruturais e superestruturais poderiam promover também a sobrevivência de uma cultura. Mas e as práticas nas quais ainda não se inferiu um valor de sobrevivência plausível?

Com efeito, defendemos que a análise da cultura por meio do modelo de seleção por consequências ainda necessita de investigações minuciosas das contingências que possibilitaram a emergência e manutenção das práticas de uma determinada cultura. Esse campo de análise é ainda baseado amplamente em inferências e, neste sentido, novos estudos descritivos de práticas culturais poderiam contribuir para que lacunas teóricas sejam preenchidas. Haveria espaço para uma etnografia comportamental na Análise do Comportamento?

\section{Considerações Finais}

As questões relacionadas com o fortalecimento e sobrevivência das culturas são importantes e com respostas imprecisas, como nosso artigo indicou. Uma vez que, quando compreendemos o comportamento humano e a evolução da cultura como decorrentes de processos de variação e seleção, apenas uma análise posterior nos indicaria quais práticas foram realmente efetivas para a sobrevivência de uma cultura. Pode-se apontar que algumas culturas têm sobrevivido ou que determinadas culturas extinguiram-se, mas quais práticas ou quais relações entre as práticas de uma cultura foram responsáveis por esses resultados ainda são inferências na Análise do Comportamento.

Uma direção, defendida neste estudo, consiste em ampliar o diálogo com teorias antropológicas que podem direcionar uma crítica ao modelo skinneriano, como fez Harris. Além disso, a Análise do Comportamento poderia utilizar as descrições minuciosas que alguns pensadores realizaram sobre diversas culturas, como os trabalhos citados de Mauss (1925/1974) e de Malinowski (1922/1984). Como enfatizamos na introdução deste artigo, respostas têm sido 
buscadas também em estudos experimentais de análogos de fenômenos culturais.

Além disso, entendemos que Skinner, ao discorrer sobre a evolução da cultura por meio de processos de variação e seleção nos direcionou para um possível programa de pesquisa no escopo do behaviorismo radical. Entretanto, ele não apresentou respostas "prontas" de como ocorre a evolução das culturas e a emergência e/ou manutenção de suas práticas. Defendemos que ele forneceu à Análise do Comportamento apenas direções. O porquê práticas complexas são mantidas e selecionadas parece carecer ainda de respostas.

\section{Referências}

Abib, J. A. D. (1996). Epistemologia, transdisciplinariedade e método. Psicologia Teoria e Pesquisa, 12, 219-229.

Andery, M. A., Micheleto, N., \& Sério, T. M. (2005). A análise de fenômenos sociais: Esboçando uma proposta para a identificação das contingências entrelaçadas e metacontingências. In J. C. Todorov, R. C. Martone, \& M. B. Moreira (Eds.), Metacontingência: Comportamento, cultura e sociedade (pp. 127-147). Santo André, SP: ESETec Editores Associados.

Biglan, A. (1995). Changing cultural practices: A contextualist framework for intervention Research. Reno, NV: Context Press.

Bullerjhann, P. B. (2009). Análogos experimentais de fenômenos sociais: Os efeitos das conseqüencias culturais. Dissertação de Mestrado, Pontifícia Universidade Católica de São Paulo, São Paulo.

Caldas, R. A. (2009). Análogos experimentais de seleção e extinção de metacontingências. Dissertação de Mestrado, Pontifícia Universidade Católica de São Paulo, São Paulo.

Carrara, K. (2008). Entre a utopia e o cotidiano: Uma análise de estratégias viáveis nos delineamentos culturais. Revista Psicologia, 1, 42-54.

Costa, D. C. (2009). Dilema do Prisioneiro: O efeito das conseqüencias individuais e culturais sobre as escolhas de cooperação e competição. Dissertação de Mestrado, Universidade de Brasília, Brasília.

Dittrich, A. (2003). Introdução à filosofia moral skinneriana. In C. E. Costa, J. C. Luzia, \& H. H. N. Sant'Anna (Eds.), Primeiros passos em análise do comportamento e cognição (pp. 11-24). Santo André, SP: ESETec Editores Associados.

Dittrich, A. (2004). Behaviorismo radical, ética e politica: Aspectos teóricos do compromisso social. Tese de Doutorado, Universidade Federal de São Carlos, São Carlos.

Dittrich, A. (2008). Sobrevivência ou colapso? B. F. Skinner, J. M. Diamond e o destino das culturas. Psicologia. Reflexão e Crítica, 21, 252-260.

Endemann, P., \& Tourinho, E. Z. (2007). Linguagem e instituições sociais em Skinner e Austin. Acta Comportamentalia, 15, 207-228.

Faleiros, P. B. (2009). Efeitos do tipo de acesso à soma da pontuação do outro jogador na emissão de respostas "cooperativas" no jogo dilema do prisioneiro repetido. Tese de Doutorado, Universidade de São Paulo, São Paulo.

Glenn, S. S. (1986). Metacontingencies in Walden Two. Behavior Analysis and Social Action, 5, 2-8.
Glenn, S. S. (1988). Contingencies and metacontingencies: Toward a synthesis of behavior analysis and cultural materialism. The Behavior Analyst, 11, 161-179.

Glenn, S. S., \& Malott, M. (2004). Complexity and selection: Implications for organizational change. Behavior and Social Issues, 13, 89-106.

Guerin, B. (1992). Behavior analysis and the social construction of knowledge. American Psychologist, 47, 1423-1432.

Guerin, B. (1994). Analyzing social behavior: Behavior analysis and the social sciences. Reno: Context Press.

Harris, M. (1980). Cultural materialism: The struggle for a science of culture. New York: Vintage Books (Trabalho original publicado em 1979).

Harris, M. (1988). Group and individual effects in selection. In A. C. Catania \& S. Harnad (Eds.), The selection of behavior. The operant behaviorism of B. F. Skinner: comments and consequences (pp. 46-47). New York: Cambridge University Press. (Trabalho original publicado em 1984).

Harris, M. (with introduction by B. Kangas). (2007). Cultural materialism and behavior analysis: Common problems and radical solutions. The Behavior Analyst, 30, 37-47. (Trabalho original apresentado em 1986).

Lamal, P. A. (1991). Behavioral analysis of societies and cultural practices. New York: Hemisphere Publishing Corporation.

Lopes, C. E. (2008). Uma proposta de definição de comportamento no behaviorismo radical. Revista Brasileira de Terapia Comportamental e Cognitiva, 10, 1-13.

Malagodi, E. F., \& Jackson, K. (1989). Behavior analyst and cultural analysis: Troubles and issues. The Behavior Analyst, 12, 17-33.

Malagodi, E. F. (1986). On radicalizing behaviorism: A call for cultural analysis. The Behavior Analyst, 9, 01-17.

Malinowski, B. K. (1984). Os Argonautas do pacífico ocidental. (A. P. Carr \& L. A. C. Mendonça, Trads.). In Coleção Os Pensadores. São Paulo: Abril Cultural. (Trabalho original publicado em 1922).

Malott. M. E., \& Glenn, S. S. (2006). Targets of intervention in cultural and behavioral change. Behavior and Social Issues, 15, 31-56.

Malott. R. W. (1988). Rule-governed behavior and behavioral anthropology. The Behavior Analyst, 11, 181-203.

Martone, R. C. (2008). Efeito de conseqüencias externas e de mudanças na constituição do grupo sobre a distribuição dos ganhos em uma metacontingência experimental. Tese de Doutorado, Universidade de Brasília, Brasília.

Mattaini, M. (1996). Envisioning cultural practices. The Behavior Analyst, 19, 257-272.

Mauss, M. (1974). Sociologia e antropologia (W. B. de Almeida, Trads.). São Paulo: Edusp. (Trabalho original publicado em 1925).

Oda, L. V. (2009). Investigação das interações verbais em um análogo experimental de metacontingência. Dissertação de Mestrado, Pontifícia Universidade Católica de São Paulo, São Paulo.

Rogers, C. R., \& Skinner, B. F. (1956). Some issues concerning the control of human behavior. Science, 124, 1057-1066.

Skinner, B. F. (1950). Are theories of learning necessary? Psychological Review, 57, 193-216.

Skinner, B. F. (1965). Science and human behavior. New York: Free Press. (Trabalho original publicado em 1953). 
Skinner, B. F. (1966). The behavior of organisms. New York: Appleton-Century-Crofts. (Trabalho originalpublicado em 1938).

Skinner, B. F. (1969). The phylogeny and ontogeny of behavior. In B. F. Skinner (Ed.), Contingencies of reinforcement: A theoretical analysis (pp. 172-217). New York: AppletonCentury-Crofts (Trabalho original publicado em 1966).

Skinner, B. F. (1976). About behaviorism. New York: Vintage Books. (Trabalho original publicado em 1974).

Skinner, B. F. (1977). Why I am not a cognitive psychologist. Behaviorism, 5, 1-10.

Skinner, B. F. (1981). Selection by consequences. Science, 213, 501-504.

Skinner, B. F. (1984). The evolution of behavior. Journal of the Experimental Analysis of Behavior, 41, 217-221.

Skinner, B. F. (1987). Why we are not acting to save the world. In B. F. Skinner (Ed.), Upon further reflection (pp. 01-14). Englewood Cliffs, New Jersey: Prentice-Hall.

Skinner, B. F. (1990). Can psychology be a science of mind? American Psychologist, 45, 1206-1210.

Skinner, B. F. (2002). Beyond freedom and dignity. Indianapolis: Hackett Publishing Company (Trabalho original publicado em 1971).
Todorov, J. C., \& Moreira, M. (2004). Análise experimental do comportamento e sociedade: Um novo foco de estudo. Psicologia: Reflexão e Crítica, 17, 25-29.

Vargas, E. A. (1985). Cultural contingencies: A review of Marvin Harris's cannibal and kings. Journal of the Experimental Analysis of Behavior, 43, 419-428.

Vichi, C. (2004). Igualdade ou desigualdade em pequeno grupo: Um análogo experimental de manipulação de uma prática cultural. Dissertação de Mestrado, Pontifícia Universidade Católica de São Paulo, São Paulo.

Wiggins, J. (1969). Status differentiation, external consequences and alternative reward distributions. In R. L. Burgess, \& D. Bushell (Eds.), Behavioral sociology: The experimental analysis of social process (pp.109-126). New York: Columbia University Press.

Recebido em 01.03.2010

Primeira decisão editorial em 22.03.2011

Versão final em 11.07.2011

Aceito em 14.07.2011 